\title{
Quality of Work Life of Independent vs Employed Family Physicians in Wisconsin: A WReN Study
}

Jobn W. Beasley, $M D^{1}$

Ben-Tzion Karsh, $\mathrm{PbD}^{2}$

Mary Ellen Hagenauer, $B A^{3}$

Lucille Marchand, $M D^{1}$

Francois Sainfort, $\mathrm{PbD}^{4}$

'Department of Family Medicine, University of Wisconsin, Madison, Wis

${ }^{2}$ Department of Industrial Engineering, and Systems Engineering Initiative in Patient Safety (SEIPS), University of Wisconsin, Madison, Wis

${ }^{3}$ Department of Orthopedics and Rehabilitation, University of Wisconsin, Madison, Wis

${ }^{4}$ Georgia Institute of Technology, Atlanta, Ga

Conflicts of interest: none reported

\section{CORRESPONDING AUTHOR}

John W. Beasley, MD

Department of Family Medicine

University of Wisconsin

777 S Mills St

Madison, WI 53521

john.beasley@fammed.wisc.edu

\begin{abstract}
PURPOSE Family physicians in Wisconsin who are mainly employed by large health care organizations have voiced concerns regarding the quality of their work lives. We explored the quality of work life and its relationship to employment by health care organizations.
\end{abstract}

METHODS We conducted a cross-sectional survey of the 1,482 active members of the Wisconsin Academy of Family Physicians in 2000.

RESULTS A 47\% overall response rate was obtained, and 584 respondents could be identified as independent or employed by a health care organization. There were no differences in age or sex between the 2 groups. The independent physicians worked longer hours, were in smaller work groups, and had been in practice longer and in their current practice longer than the employed physicians. Independent physicians reported better working relationships, more satisfaction with family time, more influence over management decisions, better satisfaction with being a physician, better perceived quality of the care they provided, greater ability to achieve professional goals, and lesser intention to leave the practice.

CONCLUSIONS Independent physicians have significantly more positive ratings of several aspects of the quality of their work life compared with physicians employed by health care organizations. Health care organizations need to address these issues if they are to have a satisfied and stable workforce.

Ann Fam Med 2005;3:500-506. DOI: 10.1370/afm.369.

\section{INTRODUCTION}

I ncreasing numbers of family physicians are employed by large health care organizations (HCOs), such as hospitals, health maintenance organizations (HMOs), vertically integrated managed care organizations, multispecialty clinics, and other entities that employ large numbers of physicians. In Wisconsin, the model of large group practices, often associated with a vertically integrated $\mathrm{HCO}$, is especially common. Because of concerns voiced by Wisconsin family physicians about their quality of work life (QOWL) in these large HCOs, the Wisconsin Research Network (WReN) (which was the research arm of the Wisconsin Academy of Family Physicians at the time of this study) collaborated with the University of Wisconsin Department of Family Medicine and Department of Industrial Engineering to do a study of the QOWL for family physicians in Wisconsin. As part of this study, we compared the QOWL for family physicians employed by HCOs with that of those in independent practices.

Our hypothesis was that independent physicians would report a generally higher QOWL than their HCO-employed counterparts. An awareness of potential problems with the quality of physician work life can help physicians and administrators in HCOs take steps to improve the QOWL for their employed physicians. 


\section{METHODS}

The methods used in this study have been previously described in detail. ${ }^{1,2}$ The study was approved by the University of Wisconsin Institutional Review Committee. During the summer of 2000, we conducted a cross-sectional survey of active members $(\mathrm{N}=1,482)$ of the Wisconsin Academy of Family Physicians, which comprises approximately $90 \%$ of all family physicians in the state. A total of 703 surveys were returned, of which 11 were undeliverable. The overall response rate was $47 \%$, which was similar to that of another recent survey of a state's family physician association. ${ }^{3}$ Of the 692 delivered and returned surveys, 64 were returned completed by participants who were ineligible because they were retired, spent less than $20 \%$ of their time in clinical practice, were unemployed, or were not a family physician. In all, 628 eligible and completed surveys constituted the sample.

\section{Study Groups}

For analysis, we grouped the physicians who were solo family physicians and members of smaller independent groups (groups not owned by a larger parent organization) into a single group - the independent group. In general, members of this group ranged from solo family physicians (very few) to independent groups of up to roughly 20 physicians. We then grouped those physicians who reported having a parent organization, such as a managed care organization, a large multispecialty group, or a hospital, into a single group - the HCOemployed group. This group included family physician-only groups and single physician offices that were owned and managed by larger HCOs. Physicians working in academic teaching practices were included in the HCO group as well. We defined the work group as "the group of physicians you work with on a daily basisgenerally, that is the people with whom you share call."

\section{Questionnaire}

The questionnaire was developed using questions from the literature and from telephone focus groups of both family physicians and their clinical assistants. The questionnaire included a total of 77 content questions (for which responses were given on Likert scales with 5 points, excepting the scale for intention to leave, which had 7 points) plus 12 demographic questions. Space was provided for open-ended comments.

On the basis of the literature and concerns of the focus groups, we selected 13 questions in 3 categories for analysis.

Four questions addressed work satisfaction issues:

1. Satisfaction with income: "How satisfied are you with your current income?" ( $0=$ not satisfied, $4=$ very satisfied. $)^{4}$

2. Amount of family time: "How satisfied are you with the amount of family time you have?" ( $0=$ not satisfied, $4=$ very satisfied. $)^{5}$

3. Quality of relationships within the work group: "How would you rate the quality of the working relationships among the physicians in your work group?" $(0=\text { poor, } 4 \text { = excellent. })^{6}$

4. Continuity of care: "How satisfied are you with your ability to provide continuity of care?" $(0=$ not satisfied, $4=$ very satisfied. $)^{7}$

The following 5 questions addressed practice issues:

1. Often work under time pressure: "How often do you work under time pressure?" $(0=\text { never, } 4=\text { always. })^{8}$

2. Amount of paperwork is reasonable: "Do you agree or disagree that the amount of paperwork you process is reasonable?" ( $0=$ strongly disagree, $4=$ strongly agree. $)^{9}$

3. Influence over management decisions: "How much influence do you have over management decisions that affect your practice?" ( 0 = very little, $4=$ very much. $)^{7}$

4. Ability to match time to complexity of patient: "How often are you able to match the amount of time you have to spend with patients to the level of complexity of each patient's case?" $(0=\text { never, } 4=\text { always. })^{10}$

5. Opportunity to fully use skills: "How satisfied are you with your opportunities to fully utilize your skills in your practice situation?" ( $0=$ not satisfied, 4 = very satisfied.) (New item from focus group.)

The following 4 questions addressed outcomes:

1. Satisfaction with being a physician: "How satisfied are you with being a physician?" ( $0=$ not satisfied, 4 = very satisfied.) (New item from focus group.)

2. Perceived quality of care: "Given your work situation in total, how would you rate the overall quality of the medical care you are able to provide?" $(0=$ poor, $4=$ excellent. $)^{11}$

3. Ability to achieve professional goals: "To what extent are you able to achieve your overall professional goals within your current practice situation?" $(0=$ not at all, $4=$ very much. $)^{12}$

4. Intention to leave the practice: "I plan to leave my work group in the near future." ( 1 = strongly disagree, 7 = strongly agree.) (New item from focus group.)

\section{Statistical Analyses}

We conducted statistical analysis with SPSS software version 11.5 (SPSS Inc, Chicago, Ill). To compare the 2 groups on demographic variables, we used the $\chi$ test for dichotomous variables (eg, sex), and we used the independent sample $t$ test with equal variance not assumed to compare means.

Three separate multivariate analyses of covariance (MANCOVAs) were used to examine whether independent physicians differed from physicians working for HCOs on the 13 study variables. The single independent variable for the 3 MANCOVAs was health care organi- 
zation, which had 2 levels: independent or HCO. The 5 covariates in each of the 3 equations were age, sex, ethnicity, hours worked per week, and years at current practice. Although the groups differed significantly in years in practice overall, this measure was highly correlated with years in current practice, so only the latter was retained. The 3 groups of dependent QOWL variables were work satisfaction issues ( 4 variables), practice issues ( 5 variables), and outcomes ( 4 variables). The Box $M$ test was used to assess homogeneity of covariance matrices. To further protect against type I error, if the omnibus $\mathrm{F}$ test for the MANCOVA was significant, it was followed by univariate $\mathrm{F}$ tests of the individual dependent variables with Bonferroni correction, after correction for the covariates.

The total $\mathrm{N}$ of 584 classified respondents (78 independents, 506 HCOs) was reduced in each of the 3 MANCOVAs (work satisfaction issues, practice issues, and outcomes) to $442(55 / 387)$, 468 (63/405), and 451 (58/393), respectively, because of missing data. Multivariate normality was not directly assessed, as the sample size in both groups far exceeded 20, the minimum typically required for robust MANOVA in the case of violations of multivariate normality. The Box $M$ test indicated violations of homogeneity of variance-covariance matrices for the work satisfaction and outcomes dependent variables, but not for the practice issue dependent variables. Inspection of the variances between the HCO-employed and independent groups for each dependent variable, however, showed that no ratios exceeded even 2:1, so the use of MANCOVA was not invalidated and the analysis proceeded as planned. ${ }^{13}$

\section{RESULTS}

The overall response rate after survey mailing and 2 follow-ups was $47 \%$, with 628 valid surveys (42\%). In all, 584 respondents could be assigned either as independent physicians or as Variables
HCO-employed physicians. Forty-four respondents were in work situations that could not be categorized as either. Among respondents, 32\% were female, 57\% were younger than age 45 , and $13 \%$ listed themselves as nonwhite and not of Hispanic origin. Work location was rural for $45 \%$ of respondents, urban for $23 \%$, and suburban for $32 \%$. Data from the American Academy of Family Physicians for that same period (American Academy of Family Physicians, G. Tollison, personal communication, June 9, 2004) confirm that the respondents were similar to the general population of Wis-
Table 1. Comparison of Independent and HCO-Employed Respondents

\begin{tabular}{lccc}
\hline Variable & Independent & HCO-Employed & $P$ Value \\
\hline Sex, female, \% & 24 & 34 & .09 \\
Age $<45$ years, \% & 49 & 58 & .17 \\
Hours worked per week, mean \pm SD & $54.2 \pm 13.8$ & $50.5 \pm 12.6$ & .04 \\
Number in work group, mean \pm SD & $9.4 \pm 7.8$ & $14.9 \pm 35.8$ & .004 \\
Years in practice, mean \pm SD & $14.4 \pm 7.8$ & $12.2 \pm 8.1$ & .03 \\
Years in present practice, mean \pm SD & $12.3 \pm 8.7$ & $8.2 \pm 8.7$ & .001 \\
\hline
\end{tabular}

$\mathrm{HCO}=$ health care organization.

Note: $\mathrm{A} \chi^{2} 2$-sided significance was used for sex and age. An independent samples $t$ test (equal variance not assumed) was used for hours worked per week, number in work group, years in practice, and years in present practice, The $\mathrm{N}$ varies from 70 to 75 for the independent group and from 470 to 496 for the HCO-employed group because respondents left some items blank.

Table 2. Comparison of Independent and HCO-Employed Respondents: Means, Standard Deviations, and Correlations for Dependent QOWL

\begin{tabular}{|c|c|c|c|c|}
\hline \multirow[b]{2}{*}{ Variable $^{\dagger}$} & \multicolumn{2}{|c|}{ Independent } & \multicolumn{2}{|c|}{ HCO-Employed } \\
\hline & Mean & SD & Mean & SD \\
\hline \multicolumn{5}{|l|}{ Work satisfaction issues } \\
\hline Satisfaction with income & 2.81 & 0.93 & 2.83 & 1.03 \\
\hline Amount of family time & 2.33 & 0.96 & 2.19 & 1.16 \\
\hline Quality of relationships within the work group & 3.30 & 0.83 & 2.80 & 1.01 \\
\hline Continuity of care & 3.44 & 0.87 & 3.32 & 0.79 \\
\hline \multicolumn{5}{|l|}{ Practice issues } \\
\hline Often work under time pressure & 3.04 & 0.75 & 3.06 & 0.77 \\
\hline Amount of paperwork is reasonable & 1.10 & 0.95 & 1.30 & 1.06 \\
\hline Influence over management decisions & 3.25 & 1.07 & 1.90 & 1.12 \\
\hline Ability to match time to complexity of patient & 2.62 & 0.69 & 2.44 & 0.81 \\
\hline Opportunity to fully use skills & 3.36 & 0.92 & 3.16 & 0.88 \\
\hline \multicolumn{5}{|l|}{ Outcomes } \\
\hline Satisfaction with being a physician & 3.48 & 0.85 & 3.26 & 0.95 \\
\hline Perceived quality of care & 3.35 & 0.62 & 3.02 & 0.63 \\
\hline Ability to achieve professional goals & 2.99 & 0.96 & 2.44 & 1.01 \\
\hline Intention to leave the practice & 1.68 & 1.35 & 2.31 & 1.85 \\
\hline
\end{tabular}

$\mathrm{HCO}=$ health care organization; QOWL = quality of work life.

Note: See the "Methods" section for a description of the scales on which variables were rated. 
consin family physicians with respect to age (56\% of respondents and of Wisconsin Academy of Family Physicians members were younger than 45 years), sex (32\% of respondents vs $28 \%$ of all Wisconsin Academy of Family Physicians members were female), and weekly work hours (mean of 51 hours for respondents vs 48.1 hours for family physicians in the Wisconsin region).

The physicians' level of satisfaction with being a physician was quite high; $83.5 \%$ of respondents were either satisfied or very satisfied with their occupation.

On classification, 78 (13\%) of respondents were in the independent group and 506 (87\%) were in the HCO-employed group. Fewer than 5\% listed themselves as being in solo practice; in fact, some who did were, as noted above, really physicians employed by HCOs. These physicians were included in the HCO group.

\section{Comparison of Independent and HCO-Employed Respondents}

Table 1 shows a comparison of the independent and HCO-employed physician groups. There were nonsignificant differences between groups for sex and age. There were significant differences for number of hours worked per week, number of individuals in the work group, years in practice, and years in the present prac- tice. The independents worked more hours per week in smaller work groups and had been in practice longer and in their present practice longer.

\section{Comparison of the QOWL Dependent Variables Between Independent and HCO-Employed Respondents}

Table 2 shows a comparison of the groups with respect to the 13 QOWL dependent variables; the values given for these variables in the text that follows are expressed in points as rated by respondents on the previously described Likert scales. Status as an independent vs HCO-employed physician was the independent variable.

\section{Work Satisfaction Issues}

For the work satisfaction issues dependent QOWL variables, the Wilks $\lambda$ was significant $\left(\mathrm{F}_{4,432}=3.99\right.$, $P=.003)$. Subsequent univariate tests for each dependent variable, with Bonferroni correction, showed that the dependent variable "satisfaction with working relationships among the physicians in your work group" differed significantly between independent and HCOemployed family physicians $\left(F_{1,435}=8.93, P=.003\right)$, with independents having more satisfaction (adjusted mean $=3.22, \mathrm{SE}=0.14)$ than $\mathrm{HCO}$ physicians

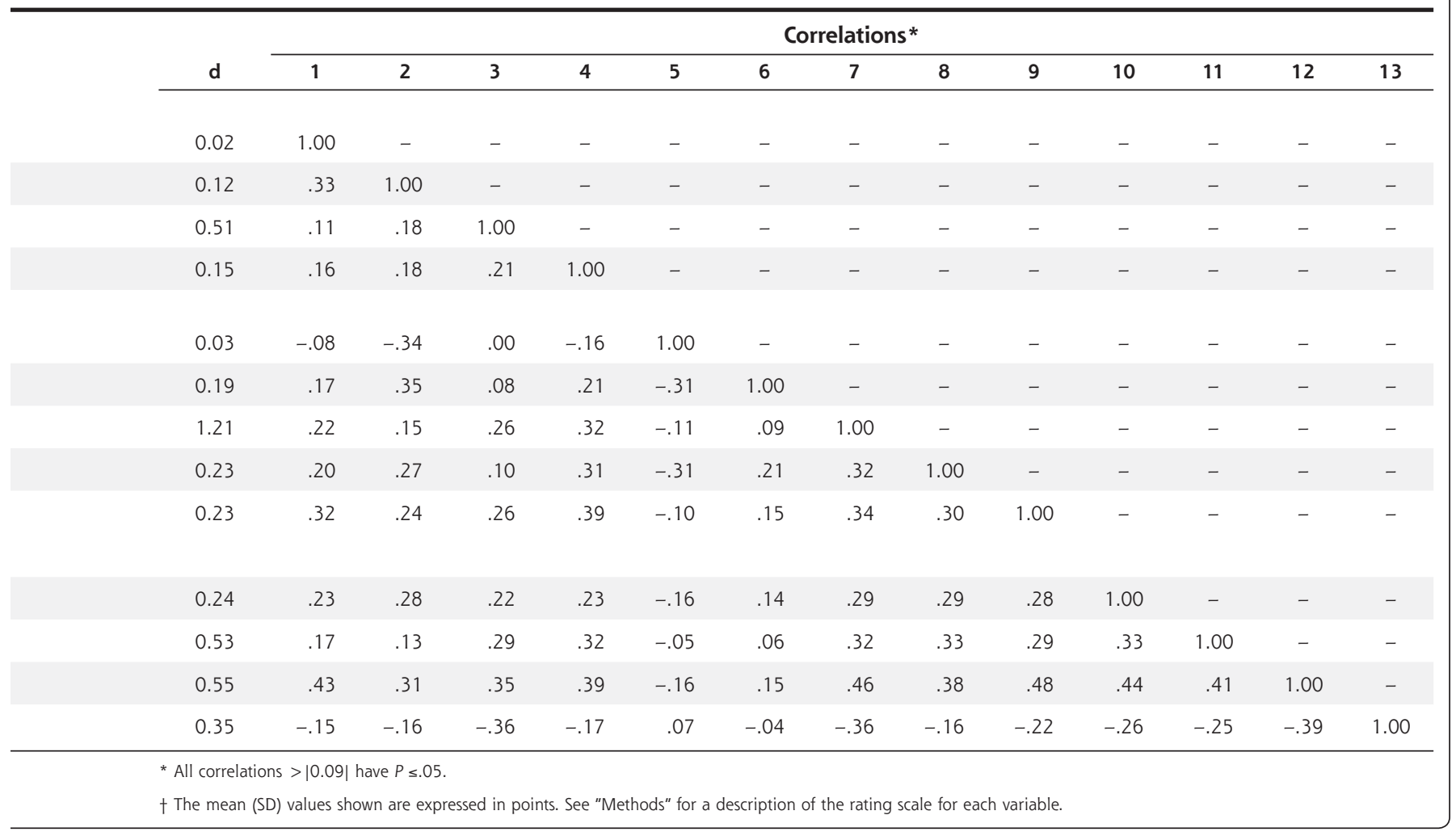


(adjusted mean $=2.78, \mathrm{SE}=0.05)$. Also, the dependent variable "satisfaction with the amount of family time you have" differed significantly between groups $\left(\mathrm{F}_{1,435}\right.$ $=7.37, P=.007$ ), with independents having more satisfaction with family time (adjusted mean $=2.53, \mathrm{SE}=$ 0.14 ) than their HCO-employed counterparts (adjusted mean $=2.13, \mathrm{SE}=0.05$ ).

\section{Practice Issues}

For the practice issues dependent QOWL variables, the Wilks $\lambda$ was significant $\left(F_{5,457}=12.34, P<.001\right)$. Subsequent univariate tests for each dependent variable, with Bonferroni correction, showed that only the dependent variable "ability to influence management decisions that affect your practice" differed significantly between independents and $\mathrm{HCO}$ physicians $\left(\mathrm{F}_{1,461}=58.88, P<.001\right)$, with independents having more ability to influence such decisions (adjusted mean $=3.12, \mathrm{SE}=0.14$ ) than $\mathrm{HCO}$ physicians (adjusted mean $=1.94, \mathrm{SE}=0.06$ ).

\section{Outcomes}

For the outcomes dependent QOWL variables, the Wilks $\lambda$ was significant $\left(F_{4,441}=5.48, P<.001\right)$. Subsequent univariate tests for each dependent variable, with Bonferroni correction, showed that all 4 of the dependent variables differed significantly between groups. The dependent variable "satisfaction with being a physician" was significantly different between groups $\left(\mathrm{F}_{1,444}\right.$ $=3.86, P=.05)$, with independents having greater satisfaction (adjusted mean $=3.50, \mathrm{SE}=0.12$ ) than HCO-employed physicians (adjusted mean $=3.24$, $\mathrm{SE}=0.05)$. The dependent variable "How would you rate the overall quality of medical care you are able to provide?" differed significantly between groups $\left(\mathrm{F}_{1,444}=\right.$ $13.68, P<.001)$, with independents rating their quality of care higher (adjusted mean $=3.34, \mathrm{SE}=0.08$ ) than $\mathrm{HCO}$ physicians (adjusted mean $=3.01, \mathrm{SE}=0.03$ ). The dependent variable "Are you able to achieve your overall professional goals within your current practice situation?" also differed significantly $\left(\mathrm{F}_{1,444}=16.32\right.$, $P<.001)$, with independents rating their ability to achieve their professional goals higher (adjusted mean $=3.01, \mathrm{SE}=0.13)$ than $\mathrm{HCO}$ physicians (adjusted mean $=2.44, \mathrm{SE}=0.05)$. The dependent variable "I plan to leave my work group in the near future" was significantly different $\left(\mathrm{F}_{1,444}=3.85, P=.05\right)$, with independents indicating that they were less likely to plan to leave (adjusted mean $=1.73, \mathrm{SE}=0.24$ ) than $\mathrm{HCO}$ physicians (adjusted mean $=2.24, \mathrm{SE}=0.09$ ).

\section{Comments by Independent and HCO-Employed Respondents}

A total of 120 physicians who could be categorized as either independent or HCO-employed physicians used the "Comments" section of the questionnaire. These physicians did not differ significantly from those who did not make comments in level of satisfaction with being a physician (3.3 vs $3.2, P=.14$ ), perceived quality of care (3.1 vs $3.0, P=.64)$, and ability to achieve professional goals ( 2.5 vs $2.4, P=.23$ ), but those providing comments were more likely to agree with the statement "I intend to leave my work group" (2.6 vs $2.1, P=.01$, where higher values reflect greater intention to leave).

Physicians often commented on satisfaction being related to having autonomy over their work life and being able to care for patients as they were trained to. Meaningful relationships with colleagues and patients added to satisfaction. Dissatisfaction was expressed over decreasing compensation despite seeing more patients, loss of autonomy over work life decisions, emphasis on productivity, overwhelming paperwork, documentation requirements, patient care decisions being made by business people, and time away from family. The number of comments expressing dissatisfaction greatly outnumbered those expressing satisfaction.

Table 3 contains some quotes from these doctors as they relate specifically to their independent or HCOemployed status. Comments relating to paperwork, payment problems, and other general issues, which did not differ substantively between independent and HCO-employed physicians, are not quoted here.

\section{DISCUSSION}

Studies have explored the relationship between payment systems and physician satisfaction ${ }^{14,15}$ and between staff-model HMO and other HMO systems. Some studies suggest HMOs are having more problems, ${ }^{15}$ while there is also evidence that employment in a staff-model HMO may have no effect ${ }^{16}$ or may be associated with greater satisfaction in some areas of practice. ${ }^{17}$ Only 1 study has explored the satisfaction of employed physicians in larger groups and found lower levels of professional satisfaction ${ }^{18}$; another study found decreased satisfaction in HMOs. ${ }^{15}$ Our study focused on the QOWL of physicians employed by differing types of $\mathrm{HCOs}-\mathrm{HMOs}$, hospitals, multispecialty clinics, or other large organizations.

The QOWL of physicians is important for HCOs as the cost of replacing a physician is about $\$ 250,000 .{ }^{19}$ There is considerable evidence of a relationship between the QOWL for physicians and other health care professionals, and patient care variables. ${ }^{20-27}$

Linzer and colleagues ${ }^{28}$ have applied the demandcontrol-support model to analyze physician stress and performance. This model suggests that the tendency to burn out generated by high demands can be balanced by greater levels of job control and social support, 


\section{Table 3. Selected Comments From Independent and HCO-Employed Physicians}

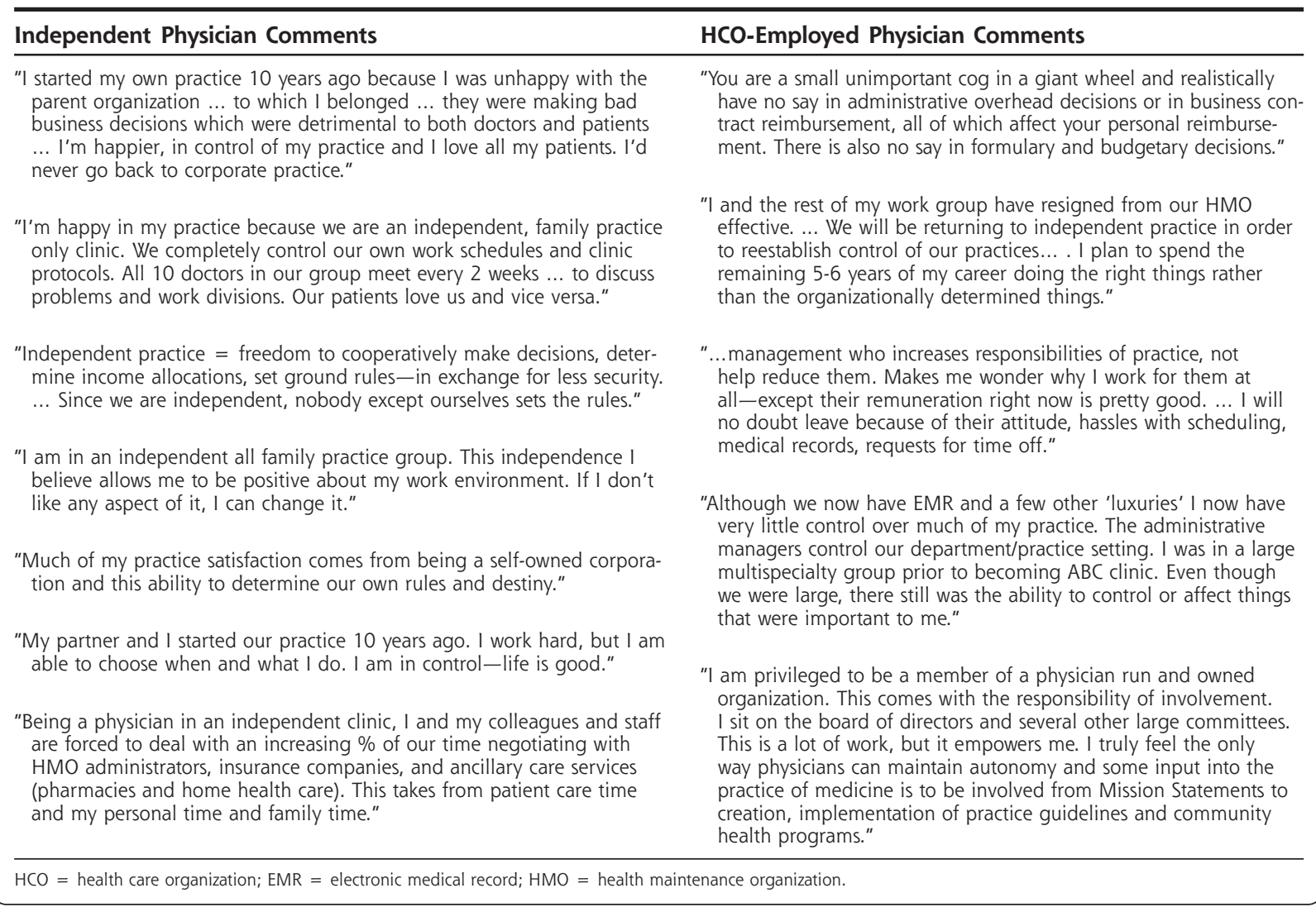

at least within limits. In our study, the largest difference between the independent and $\mathrm{HCO}$-employed respondents was in the level of influence over management decisions, where the HCO-employed physicians perceived that they had a much lower level of control. The second largest difference between the independents and the HCO-employed physicians among workplace satisfaction variables was in the working relationships in the group. These factors taken together suggest that physicians employed by HCOs are lacking both in control and in social support relative to their independent colleagues.

Our findings regarding outcome measures are cause for concern as more physicians move into employed status. Physicians employed by HCOs rated the quality of care they could provide as lower, were less able to achieve their professional goals, and were more likely to intend to leave their work group. Whether these physicians' subjective measures translate into an actual lower quality of care or greater likelihood of leaving the practice cannot be determined from this study, but the literature cited above certainly suggests a relationship between the physicians' reports and reality. The weight of the evidence suggests that if HCOs take steps to improve the QOWL of their physicians, they can antic- ipate improved care, greater patient satisfaction, and decreased physician turnover. Existing guidelines outline how various employment factors can be modified to create healthier, more efficient organizations. ${ }^{27}$

There are several limitations to this study. Although the respondents were representative of Wisconsin family physicians generally, there could have been response bias between the independent and the HCOemployed groups. In addition, the definition of independent vs HCO-employed was somewhat arbitrary. Some HCOs are physician owned and operated; others are not. Some independent groups were quite large, whereas some $\mathrm{HCO}$ physicians actually had very small work groups. In addition, the degree of control by the $\mathrm{HCO}$ could be very different in, for example, a rural satellite clinic vs the main facility. Finally, the division of the variables into somewhat arbitrary definitions of work satisfaction issues, practice issues, and outcomes suggests a degree of causality that may not be present. Future work will explore the relationship between the practice variables in various HCOs that influence physicians and the outcomes for the physicians' QOWL.

Independent physicians have more positive ratings for their relationships within the work group, the amount of family time, their influence over manage- 
ment decisions, their overall satisfaction with being a physician, their perceived quality of care, and their ability to achieve their professional goals. In addition, they state a lesser intention to leave the practice than physicians employed by HCOs.

Physicians employed by HCOs face substantial problems relative to independent physicians. Problems such as the lack of input into management decisions affecting practice and the apparent suboptimal relationships between physicians in the work group can be resolved or mitigated. HCOs can have a more satisfied effective, and stable workforce if they address these problems. These issues will become increasingly important as the trend toward more physicians working as employees of HCOs continues.

To read or post commentaries in response to this article, see it online at http://www.annfammed.org/cgi/content/full/3/6/500.

Key words: Physicians, family; job satisfaction; primary care; health care economics and organizations; managed care programs; health care delivery/health services research; practice-based research

Submitted July 22, 2004; submitted, revised, April 24, 2005; accepted May 18, 2005.

Portions of this work have been presented at the American Academy of Family Physicians National Network Convocation, March 19, 2004, Kansas City, Mo; the Wisconsin Academy of Family Physicians' Annual Primary Care Research Forum, January 30, 2004, Oconomowoc, Wis; the Wisconsin Medical Society Conference From Dissatisfaction to Action, November 6, 2003, Green Lake, Wis; the American Academy of Family Physicians Annual Leadership Forum, May 1-3, 2003, Kansas City, Mo; and the American Academy of Family Physicians Annual Leadership Forum, April 26-27, 2002, Kansas City, Mo. Portions of this work focusing on different aspects of this topic have been published in references 1 and 2 .

Funding support: This study was funded by the Center for Quality and Productivity Improvement, the Wisconsin Academy of Family Physicians, and its research arm at that time, the Wisconsin Research Network (WReN).

Acknowledgments: The authors would like to thank Mary Stone and Pamela Weisen, MBA, for coordinating focus group meetings, recruiting participants, and contributing to the execution of the study. They also thank Randy Munson and Fred Moskol, RPh, of the University of Wisconsin Office of Rural Health for invaluable help in linking physicians to the various health care organizations. Finally, we are most grateful to the physicians who took the time to participate in the focus groups and respond to the survey.

\section{References}

1. Karsh B, Beasley JW, Hagenauer ME. Are electronic medical records associated with improved perceptions of the quality of medical records, working conditions, or quality of working life? Behav Info Technol. 2004;23:327-335.

2. Beasley JW, Karsh BT, Sainfort F, Hagenauer ME, Marchand L. Quality of work life of family physicians in Wisconsin's health care organizations: a WReN study. Wis Med J. 2004;103:51-55.

3. Loomis GA, Ries JS, Saywell RM Jr, Thakker NR. If electronic medical records are so great, why aren't family physicians using them? J Fam Pract. 2002;51:636-641.
4. Arnetz BB. Physicians' view of their work environment and organisation. Psychother Psychosom. 1997;66:155-162.

5. Skolnik NS, Smith DR, Diamond J. Professional satisfaction and dissatisfaction of family physicians. J Fam Pract. 1993;37:257-263.

6. Freeborn DK. Satisfaction, commitment, and psychological well-being among HMO physicians. West J Med. 2001;174:13-18.

7. Gazewood JD, Longo DR, Madsen R. Physician satisfaction with Medicaid managed care: the Missouri experience. J Fam Pract. 2000;49:20-26.

8. de Jonge J, van Breukelen JP, Landeweerd JA, Nijhuis JN. Comparing group and individual level assessments of job characteristics in testing the job demand-control model: a multilevel approach. Hum Relations. 1999;52:95-122.

9. Schulz R, Scheckler WE, Moberg DP, Johnson PR. Changing nature of physician satisfaction with health maintenance organization and feefor-service practices. J Fam Pract. 1997;45:321-330.

10. Linzer M. The Physician Worklife Study: the results are in! SGIM Forum. 1998;21:2, 9-10.

11. Deckard G, Meterko M, Field D. Physician burnout: an examination of personal, professional, and organizational relationships. Med Care. 1994;32:745-754.

12. DeLisa JA, Kirshblum S, Jain SS, et al. Practice and career satisfaction among physiatrists: a national survey. Am J Phys Med Rehabil. 1997;76:90-101.

13. Tabachnick BG, Fidell LS. Using Multivariate Statistics. 3rd ed. New York, NY: HarperCollins College Publishers; 1996.

14. Schulz R, Girard C, Scheckler WE. Physician satisfaction in a managed care environment. J Fam Pract. 1992;34:298-304.

15. Linzer M, Konrad TR, Douglas J, et al. Managed care, time pressure, and physician job satisfaction: results from the Physician Worklife Study. J Gen Intern Med. 2000; 15:441-450.

16. Buchbinder SB, Melick CF, Powe NR. Managed care and primary care physicians' overall career satisfaction. J Health Care Finance. 2001;28:35-44

17. Chehab EL, Panicker N, Alper PR, et al. The impact of practice setting on physician perceptions of the quality of practice and patient care in the managed care era. Arch Intern Med. 2001;161:202-211.

18. Grembowski D, Ulrich CM, Paschane D, et al. Managed care and primary physician satisfaction. J Am Board Fam Pract. 2003;16:383-393.

19. Buchbinder SB, Wilson M, Melick CF, Powe NR. Estimates of costs of primary care physician turnover. Am J Manag Care. 1999;5:1431-1438.

20. Aiken LH, Clarke SP, Sloane DM, Sochalski J, Silber JH. Hospital nurse staffing and patient mortality, nurse burnout, and job dissatisfaction. JAMA. 2002;288:1987-1993.

21. DeVoe J, Fryer GE Jr, Hargraves JL, Phillips RL, Green LA. Does career dissatisfaction affect the ability of family physicians to deliver highquality patient care? J Fam Pract. 2002;51:223-228.

22. Shanafelt TD, Bradley KA, Wipf JE, Back AL. Burnout and self-reported patient care in an internal medicine residency program. Ann Intern Med. 2002;136:358-367.

23. DiMatteo MR, Sherbourne CD, Hays RD, et al. Physicians' characteristics influence patients' adherence to medical treatment: results from the Medical Outcomes Study. Health Psychol. 1993;12:93-102.

24. Linn LS, Brook RH, Clark VA, et al. Physician and patient satisfaction as factors related to the organization of internal medicine group practices. Med Care. 1985;23:1171-1178.

25. Haas JS, Cook EF, Puopolo AL, et al. Is the professional satisfaction of general internists associated with patient satisfaction? J Gen Intern Med. 2000;15:122-128.

26. Firth-Cozens J. Interventions to improve physicians' well-being and patient care. Soc Sci Med. 2001;52:215-222.

27. Sainfort F, Karsh BT, Booske BC, Smith MJ. Applying quality improvement principles to achieve healthy work organizations. Jt Comm J Qual Improv. 2001;27:469-483.

28. Linzer M, Gerrity M, Douglas JA, et al. Physician stress: results from the Physician Worklife Study. Stress Health. 2002;18:37-42. 